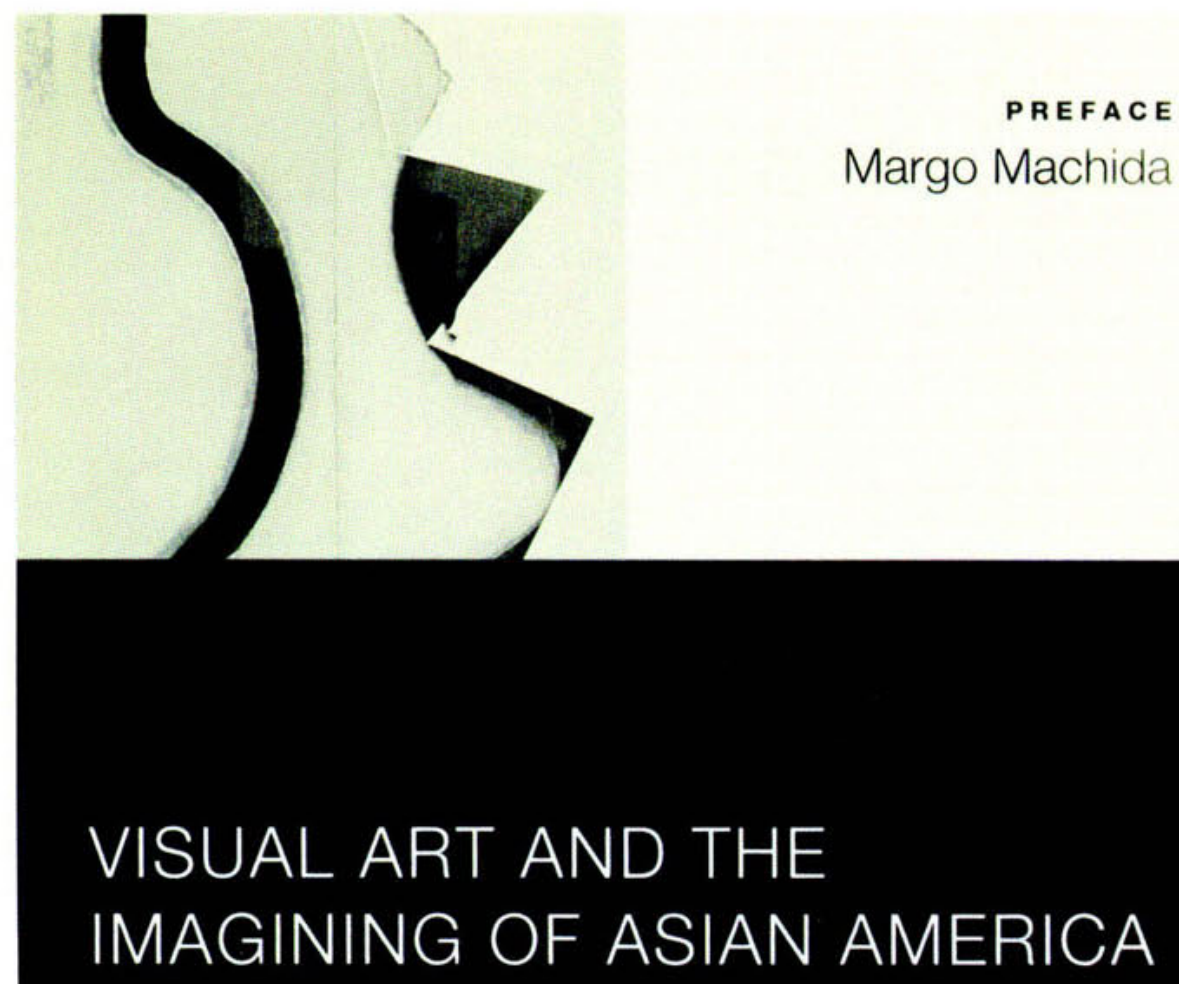

An Editorial View

FRESH TALK / DARING GAZES PROVIDES A FORUM FOR WIDE-RANGING DIALOGUE ABOUT art produced by people of Asian heritage in the United States. Exploratory in orientation and extending over a number of years, Fresh Talk is the result of a bicoastal collaboration that reflects the rewards and considerable challenges of bringing together differing editorial visions and a diverse group of artists and writers in a joint endeavor. At its core is a collection of short interpretive essays by twenty-four commentators, each paired with an Asian American visual artist. The contributors are cultural critics, artists, social activists, curators, and scholars whose responses range from the theoretical and political to the highly personal. These relatively brief reflections are juxtaposed with more extended essays by Lisa Lowe and Elaine Kim, who offer their perspectives on Asian American cultural production, as well as with captions by Sharon Mizota, intended to bring forward salient themes in the featured artists' work.

The narratives and voices convened in this volume may at times seem cacophonous. Yet the connections and overlapping interests, as well as the discontinuities and disjunctions, evident among these writings reflect the multivalent nature of discourse in and about present-day Asian America. In such an extraordinarily complex and continually expanding community, embracing a wide range of ethnic, national, cultural, and religious her- 
itages as well as divergent migration histories and experiences in this nation, no single standpoint, defining motif, or ideology predominates.

Beyond being an occasion for everyone involved to think broadly and imaginatively, Fresh Talk can best be understood as a locus for intertextual dialogue and debate. The book has been substantially restructured since it was launched in the early 1990 s as a pictorial reference work intended to document art produced by individuals of Asian background. As a cultural critic and curator specializing in this area of research, I was invited to join the editorial team in 1995, shortly after I had organized the nationally touring exhibition ASIA/AMERICA: Identities in Contemporary Asian American Art for the Asia Society Galleries in New York City. This thematic group show featured twenty immigrant and refugee artists from China, Japan, Korea, the Philippines, Thailand, Laos, Vietnam, and India whose work addressed questions of identity formation that arise in the process of traversing cultures and situating oneself in a new country. ASIA/AMERICA enabled me to discern the broad contours of cultural production arising from the experiences of Asian-born artists in the U.S. diaspora.

The highly polarized critical debate surrounding that show underscored the extent to which Asian American art, especially when it addresses issues of identity, may be associated with seemingly intractable problems linked to domestic race politics and the rhetoric of victimization. As a result, artists of Asian background are all too often perceived as yet another minoritized group encasing themselves in an exclusionary cultural armor while also clamoring for mainstream recognition. Despite the fact that the art may address issues of migration, border crossing, cultural difference, historical connections between the United States and Asia, the politics of representation, and a host of other concerns that potentially affect everyone, framing those issues through an Asian American lens continues to be widely regarded as parochial and self-marginalizing. While certainly cognizant of such arguments, I maintain that there is nothing inherently restrictive, essentialist, or balkanizing about concepts like difference and identity; rather, they can be as capacious and supple as our imaginations will allow. However, many commentators tend to collapse important distinctions by equating any interest in cultural specificity with cultural essentialism and cultural nationalism, thereby narrowing the scope of critical thought rather than inviting further investigation.

Coming to this project after ASIA/AMERICA, I was acutely aware of how profoundly the intellectual and ideological climate that informed the original editors had shifted. Given the mounting criticism of multiculturalism and identity politics in the mainstream and minoritized arts communities alike that began in the 1980 s, as well as the impact of critical theory in all areas of artistic discourse and cultural production, I believed that simply reproducing images of Asian American art without also seeking new means to interpret and to contextualize it would be problematic. Certainly to the extent that historical and cultural accounts of a period will tend to reflect the standpoints and needs of the dominant group, minoritized communities must push to place their images and ideas before the public. However, I would argue that to effect change at the level of discourse, the challenge for scholarship is not only to present Asian American visual art, but also to develop strategies to make the sweep of the perspectives and emotions that animate it more intel- 
ligible to art audiences, thereby extending its producers' insights to a broader public and rendering that art socially useful and influential beyond narrow circles of specialists.

The domestic experience, by more and more reflecting an international circulation of peoples and ideas, is impelling growing numbers of individuals of all backgrounds to confront fundamental questions surrounding cultural identity, citizenship, and their sense of place in the world. As the American art world, like society in general, becomes an increasingly hybrid, transnational environment, fundamental issues of meaning and cultural translation are assuming an ever more prominent position. This fact is eloquently noted by Homi K. Bhabha, whose 1998 conversation with artist Shahzia Sikander appears in this collection: "Supposing we don't want an exoticism, we don't want an orientalism . . . what kind of intercultural knowledge is necessary? . . What must I know? . . What must I be as a citizen spectator?"

In this atmosphere, a pivotal question has been how to situate a project like Fresh Talk, which by definition does foreground certain ethnic identities, while at the same time signaling the clear intention to move beyond extant rhetorics of race and ethnicity in framing the art. In this, it is not simply a politics of inclusion that informs our efforts (i.e., for Asian Americans to put forward images they create as a counterweight to imposed stereotypes and omissions), but rather an interest in generating new ways of thinking about this art.

By opening up new lines of communication and cross-identification, Fresh Talk's framework is a manifestation of these guiding concerns. It provides the grounds for direct engagement with members of other groups in acts of meaning-making, and thus extends the discourse arising from contemporary Asian American experience to broader publics. Much as some in Asian American studies actively position the Asian presence in more broadly relational and globalized terms, thereby challenging racialized discourses that reify schisms between groups in the domestic sphere, the editors of Fresh Talk are particularly interested in fomenting exchange among members of minoritized communities who have had too few opportunities to reflect on one another's cultural production. The decision to solicit primarily (although not exclusively) writers of other non-European heritages (African American, Latino, and Native American) - - number of whom had never previously written about Asian American artists--was informed by a double commitment: to advance significant interchange between Asians and other peoples of color, and to put forward perspectives and analysis that can challenge Eurocentric interpretations.

Encountering artists and works of art with which they were largely unfamiliar afforded the writers in Fresh Talk an unusual opportunity to reflect on how they construct meaning when looking at and writing about art, and on what culturally and historically specific frames of reference they bring to that process. Many richly configured cross-readings have resulted, such as Jolene Rickard's interpretation of Japanese American printmaker and installation artist Tomie Arai's work refracted through the prism of her Native American spiritual and cultural practices, or Nigerian-born artist and critic Odili Donald Odita's invocation of his own family's forced migration during the Biafran civil war in situating the work of Vietnamese refugee photographer Pipo Nguyen-Duy. Some essayists engage with the artists directly; others focus on the artworks themselves. Whatever form those in- 
terpretive exchanges may take, they are in microcosm the types of efforts we must make in a polycultural society that requires ever increasing negotiations of multiple realms of difference.

\section{The Selection Process}

Early in the project, there was an open call for submissions of slides. Drawing on that original material as well as our own research, the editorial team submitted visual works for joint review, balancing concern with artists' ethnic background, gender, geographic location, and the type of issues addressed in their work. The editors then solicited the participating artists to determine whether there were particular individuals with whom they especially wanted to be in conversation.

Dialogue and collaboration, therefore, not only provide a conceptual scaffold for the book itself, but also constitute the working method integral to its organization as the contributors, like the featured artists, were jointly selected by the editorial team through a painstaking process of deliberation and negotiation. Writers with differing orientations and approaches known for their broad interests in visual art and cultural politics, who could bring sharply honed and distinctive insights to this project, were identified and solicited. Notably, a number of the essayists are artist-scholar-activists who have played a pivotal role in the development of their own fields in the last few decades, and as a result were especially responsive to the project. In addition to such established figures, the editors believed it was also crucial to bring in younger writers to engage in intergenerational conversation.

Clearly such a process is difficult at best, as many commentators as well as artists deserving of recognition could not be included or were unable to participate. It must be emphasized, therefore, that Fresh Talk is not intended to offer a comprehensive overview of the field. Rather it points to certain intriguing lines of inquiry and currents of crossidentification that contemporary Asian American artists and cultural critics are now pursuing.

\section{Fresh Talk as a Communitarian Project}

While the writers and artists assembled here do not necessarily know or maintain ongoing contact with one another, and their backgrounds and concerns vary substantially, they all committed themselves to an experimental project that places primary importance on acts of interpretation across registers of difference. It is our hope that making Asian American visual art the center of this expansive, often unruly discussion has functioned as a form of communitarian endeavor, one that permits the participating artists and writers to see themselves as active agents and fellow contributors to a larger continuum of knowledge around common subjects.

In invoking communitarianism, I recognize that current notions of community are neither transparent nor static. As traditional assumptions of communities based on nationality, ethnicity, familial ties, or continuous presence in one place are increasingly destabilized and challenged, new concepts and approaches are needed to point to emerging lines of affiliation, channels of communication, and spaces of transmission that have the po- 
tential to expand our notions of how such ideas are conceived and enacted. Literary scholar and oral historian Rina Benmayor cogently observes that there are no overriding reasons to view community as something "restricted to geographic location or national homogeneity. Rather, community consists of collective formations of individuals tied together through common bonds of interest and solidarity."

In the arena of the arts, as feminist art historian Arlene Raven notes, "The critical context is part of the concept of 'community.' Unlike standard definitions of community as individuals with common interests based on location alone (such as a state or commonwealth), the community that consists of artists and audience for artworks contains, as well, the commentative structure in which the audience and artist may view the process and product of art making."

To foreground such emerging connections, I offer the term commumities of imagination as a flexible and porous conception of community in which the sense of sharing something with others, whether based in common lived experiences, belief systems, or membership in a culture or polity, is made tangible through the visual arts. While communitics of imagination plays off Imagined Communities, the title of Benedict Anderson's groundbreaking work on the development of the modern nation-state, my use of the term is not intended to suggest a systemic or deconstructionist approach to the notion of community. Rather, the inverted phrasing is meant to evoke something more elusive, the generative capacity of the artistic imagination in producing a sense of collectivity or affiliation among people, both as groups and as individuals, through themes and narratives requisite to conceptions of community and culture. ${ }^{3}$ As a communicative act, a work of art projects the maker's images, ideas, and meanings into the sphere of the social imagination, where it circulates among other conversations that overlap and cut across traditionally accepted lines of identification. In giving concrete form to an individual's sensibilities and experience, art objects are readily perceptible points of identification capturing and extending the imagination of viewers, allowing them to better recognize aspects of themselves and their lives through engagement with the work.

In the long run, interchanges like these have the power to produce a kindling effect, sparking new ways to think and write about art. As the artists, artworks, and essays in Fresh Talk attest, we live in a fully intra-contextual social terrain. Since the geography of Asian America is ultimately both real and imagined, interactive and open-ended projects like Fresh Tulk are valuable in providing different levels of focalization through which to consider and respond to the myriad public and private circumstances, discourses, and imaginative transactions that simultaneously vex and bind the lives of Asians in this country. 
